\title{
A Hardened CARS System Utilized for Temperature Measurements in a Supersonic Combustor
}

\author{
Richard R. Antcliff*, Michael W. Smith, Olin Jarrett, Jr., G. Burton Northam* \\ NASA Langley Research Center, Hampton, Virginia
}

\author{
Andrew D. Cutler \\ George Washington University, Hampton, Virginia \\ David J. Taylor* \\ Los Alamos National Laboratory, Los Alamos, New Mexico
}

\section{Abstract}

A coherent anti-Stokes Raman scattering (CARS) system has been hardened for use in a NASA Langley supersonic combustion test cell. The system can obtain temperature cross sections of the flow at three locations. The system is environmentally protected and remotely operated.

Measurements were made in ascramjet combustor model consisting of a rearward-facing step, followed by an expansion duct. The duct is nominally 4 feet in length. The free stream conditions were Mach 2, with static pressure which ranged from 0.8 to $1.9 \mathrm{~atm}$, and a static temperature of approximately $800 \mathrm{~K}$. Three vertical slots were machined into each side of the duct to allow optical access.

The CARS system utilized a planar BOXCARS beam arrangement. This arrangement allowed the laser beams to pass through the vertical slots in the tunnel. Translation stages were utilized to move the focussing volume within the tunnel. These stages allowed complete cross sections to be obtained at each slot location. A fiber optic carried the signal to a remotely located monochrometer and reticon detector.

* Member AIAA

Copyright (이일 1990 by the American Institute of Aeronautics and Astronautics, Inc. No copyright is asserted in the United States under Title 17, U.S. Code. The U.S. Government has the royalty-free license to exercise all rights under the copyright claimed herein for Governmental purposes. All other rights are reserved by the copyright owner.
Data for two different flow conditions were taken at each of the three slot locations. These two conditions provided a comparison between reacting and non-reacting mixing of injected hydrogen fuel with the combustion heated supersonic stream.

\section{Introduction}

The recent emphasis on hypersonic flow has intensified the importance of measurements in ground facilities which can simulate these flow conditions. The Langley Hypersonic Test Cells have been used extensively to test supersonic combustion ramjet components. Data available from these facilities have been limited by the instrumentation systems which are typically wall pressure and temperature probes and force measurements. There is a great desire to obtain measurements within the flow itself. Rake mounted probe measurements not only introduce perturbations to the flow but they are limited by survivability in harsh combustion environments. Non-intrusive measurements have been shown to have great promise to obtain much needed information. However, very few systems have been successfully coupled with harsh combustion environments $1,2,3$.

\section{Experimental Apparatus}

\section{CARS System}

The current CARS system is an adaptation of a system which has been described in detail 


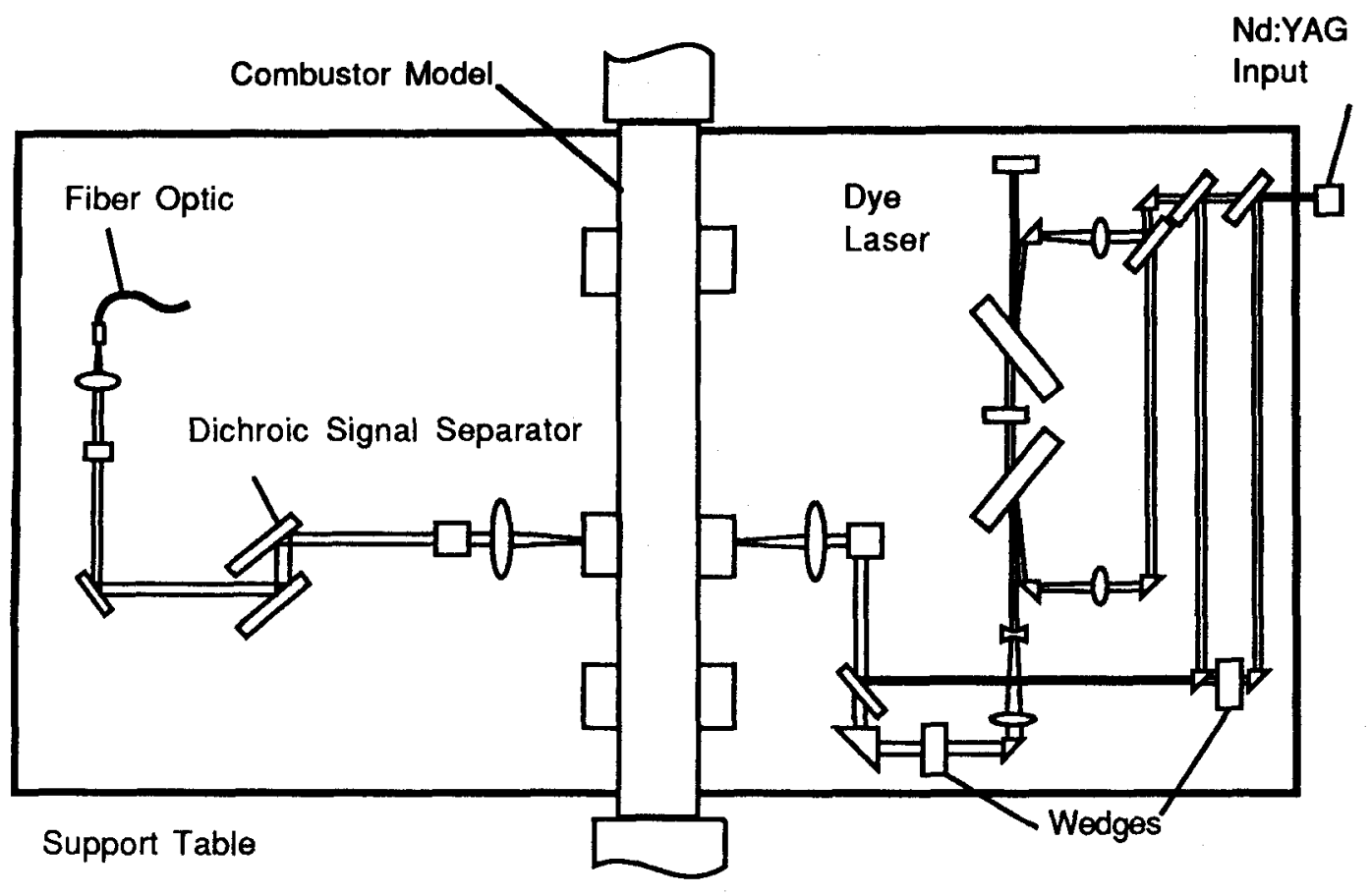

Figure 1. Schematic of the CARS optical system

elsewhere ${ }^{4}$. However, the layout has been changed dramatically due to the constraints of the Test Cell environment. These changes and their affect on the CARS system performance will be described.

A special mounting structure was constructed to support and protect the optical components. The structure consisted of a Klinger frame surrounded by sheet metal forming an enclosed box. All of the optical components including the laser were placed inside this box. A low flow air purge was placed inside the box to produce a slight positive pressure. This aided in 1) eliminating dust from the optical environment, 2) cxcluding combustible gases from the electrical systems and 3 ) providing limited air temperature stability. The box also blocked all stray laser radiation so that it was not a hazard to tunnel personncl. The noise environment in the test cell was an initial concern. Measurements were made of white noise levels up to $150 \mathrm{db}$. Acoustic insulating foam was purchased to provide noise damping, however, it was not found to be necessary.

The main laser system was a ND:YAG laser doubled to $532 \mathrm{~nm}$. This laser produced $\sim 10$ nsec laser pulses at $10 \mathrm{~Hz}$ of $200 \mathrm{~mJ}$. The power supply for this laser was located in an adjacent room with the umbilical cord run into the Test Cell. The laser head was positioned on the bottom platform of the two platform structure. From here the laser beam was directed to the top platform where the remainder of the optics were positioned. Figure 1 is a schematic of the top platform. The 532 beam was split into three equal beams. One of these beams was used to pump a broad-band dye laser centered at $607 \mathrm{~nm}$. This wavelength is required to probe the $Q$ branch of nitrogen. The dye laser was a simple off-axis pumped oscillator and amplifier. The remaining two beams are used as "pump" beams for a BOXCARS alignment.

To provide remote adjustment of the laser beams, rotating wedge assemblies were placed in the dye beam and one of the "pump" beams. These assemblies each contained two wedges which werc independently rotated to allow precise adjustment of the laser beams from the control room. The three laser beams [two "pump", one dye] were combined on a dichroic and directed to a complex translation stage. This translation system allows the input laser beams and output signal to be tracked as the measurement location is changed remotely. The translation system provided for motion in the two 


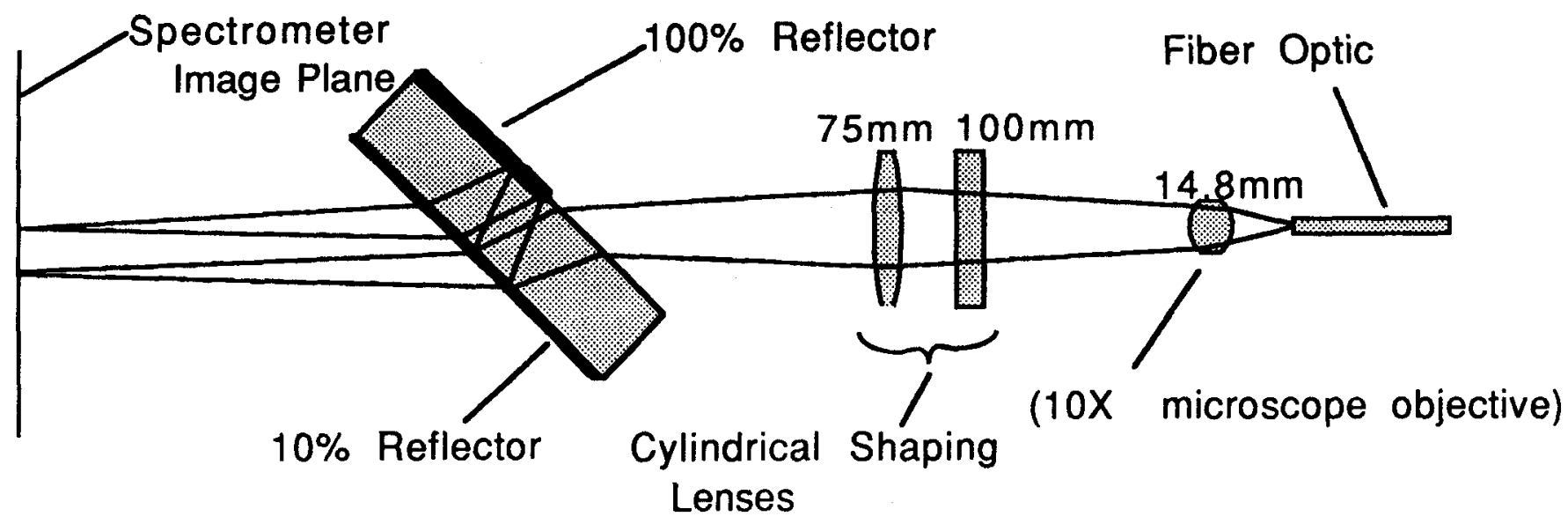

Figure 2. Signal-conditioning optics at the entrance to the monochrometer

axes normal to the flow, allowing cross sectional measurements to be made.

The laser beams were aligned in a planar BOXCARS configuration with the plane set vertically. The interaction volume was found experimentally to be less than 1 $\mathrm{mm}$. The optical access will be discussed later. On the receiving side of the tunnel the signal was directed into a multi-pass dichroic to separate the signal from the input lasers ${ }^{5}$. The signal was then focussed onto a 50 micron fiber. This fiber carried the signal to the adjacent control room. The signal was then coupled to the monochrometer so as to obtain a line image ${ }^{6,7}$. An optical splitter was used similar to that of Eckbreth 8 to increase the dynamic range of the detector by creating multiple images. The two images created on the detector were produced at two different intensities. The data reduction software could then choose which of the images was in an acceptable intensity range. Figure 2 is a schematic of this system. Finally, the signals were imaged through a 1 meter monochrometer onto a photodiode array.

\section{Test Cell}

The Langley Hypersonic Test Cell \#2 is presently configured with a vitiated air heater supplying a Mach 2 nozzlc. Downstream of the nozzle [2.7 inches] is located a rearward facing step [0.3 inches] to enhance mixing. A transverse hydrogen injector is located another 3 inches downstream. The tunnel then diverges on one wall at $3^{\circ}$. The expansion duct was approxi- mately 4 feet long with a cross section starting at $3.46^{\prime \prime}$ wide by $1.818^{\prime \prime}$ high expanding to 4.3" high. The total temperatures obtained were typically $1440 \mathrm{~K}$ yeilding a static temperature of $800 \mathrm{~K}$.

Three vertical slots were machined into the wall of the tunnel to provide optical access. These were located at 12.3, 27.3 and 42.9 inches downstream of the rearward facing step. Special windows were constructed for these slots. Each window was individually shuttered to protect the optics from startup and shutdown of the tunnel. In addition, the windows were recessed from the tunnel wall and purged with nitrogen to keep debris from accumulating on the windows.

\section{Measurements}

\section{Data Collection}

The data collection system was based on a MODCOMP mini-computer. This computer controlled the collection of reticon data, movement of the translations system and control of the remote laser beam adjustment. The tunnel typically operated for approximatcly 10 seconds if hydrogen was injected or 35 seconds if it was not. This limited run time was simply due to heating of the tunnel materials. The normal data collection cycle was as follows. The laser system was brought up, aligned and allowed to stabilize. Once good signal levels were attained and the system was stable, the "box" was closed and we no longer had hand-on access. At this point the tunnel technicians entered the test cell to prepare the tunnel for run- 
ning. Part of their procedure was to open large vents which allowed ambient air to sweep through the test cell. This air dramatically changed the temperature within the cell. Remote adjustments to the optics were required to compensate for any temperature produced misalignments. Once the tunnels technicians were finished the tunnel was scaled and no further access was allowed until after the test.

The tunnel controls were then set to the desired operating conditions and prepared to run. The run signal given to the tunnel was also sent to the CARS data acquisition system to initiate data collection. This allowed us to compare tunnel events to CARS data. A preset delay opened the optical access windows after the tunnel was started. This allowed the laser beams to pass through the tunnel and generate signal. Data was stored on a 9-track tape for later data reduction. At a preset time before the tunnel shut down the window shutters closed and the CARS data collection ceased. Run durations were typaccly 10 to 30 seconds. Turn around time for the tunnel was approximately 15 minutes. During this time the laser beam alignment was checked to see if adjustments were necessary to maximize signal levels.

\section{Data Reduction}

The data reduction procedure has been discussed in detail 4 . In general, the data are read from tape, a detector background curve is subtracted and the software decides which if the two peaks is of the appropriate intensity. The experimental data are compared to a library of precalculated spectra through a least squares fit. The temperature of the media being investigated is dependant only on the shape of the spectra through the Boltzman distribution. An instrument function which is dependant on the laser linewidths and the monochrometer slit function is determined empirically by fitting data of known temperature.

During a typical tunnel run, 20 laser shots of data were obtained at a particular point in space. The point was than moved and 20 more shots of data were collected. At some locations [high density gradients] this process was repeated sevcral times to obtain confidence in the measurements. The individual shots were fit to temperature and than the temperatures were averaged to produce the data plots shown in the figures below. The cross sectional grid for data col- lection in the $x$ direction was nine points separated by 0.375 inches about the center line. In the $y$ direction the grid changed as the tunnel diverged. At the first station the 7 points were taken every 0.28 inches; at the second station 6 points were taken every 0.48 inches; at the third station 6 points were taken every 0.64 inches. Data were taken approximately 0.5 inches from the wall to minimizes laser interference and window damage.

\section{Results \& Discussion}

Data were obtained under two sets of tunnel conditions. The first set was taken with only the heater on and no injection of hydrogen. In general the data in these cases was very uniform across the duct. Figure 3 shows a sample of this data obtained at station 3 . The scale on this data is greatly expanded to show some very weak structure in this data. There does appear to be some weak cooler zones on either side of the centerline. These may be due to weak vortices formed in the duct.

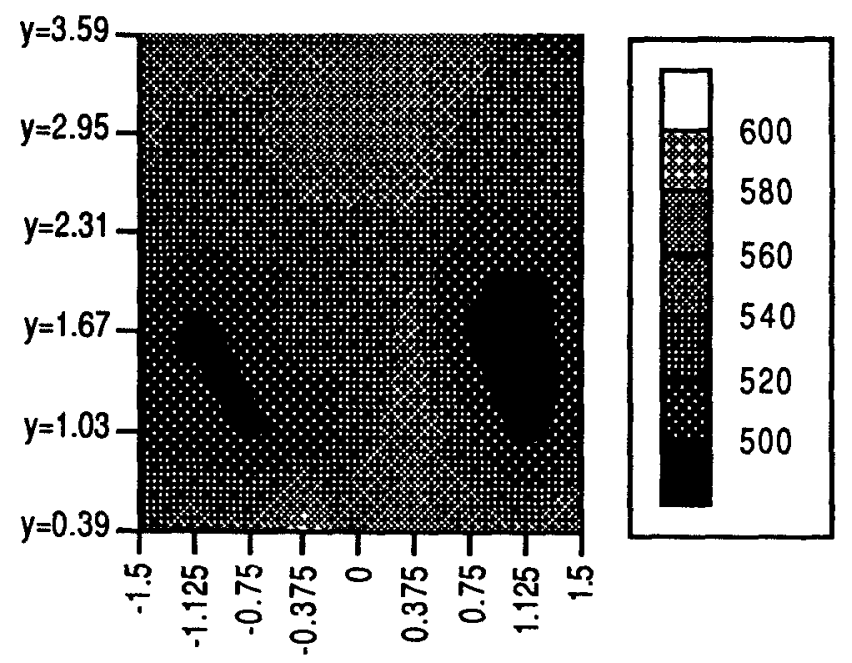

Figure 3 Heater only temperature data ${ }^{\circ} \mathrm{K}$

The second set of data was taken with the hydrogen injection on ${ }^{9}$. This data is shown in the multiple plot in Figure 4. The plot shows the cross sectional temperatures obtained at the three stations. These data indicate a hot combusting zone beginning at the injection wall and slowly spreading out downstream.

Some further details regarding the data can be seen if a slice is taken across one of cross section. In particular, Figure $5 \mathrm{a}$ is 


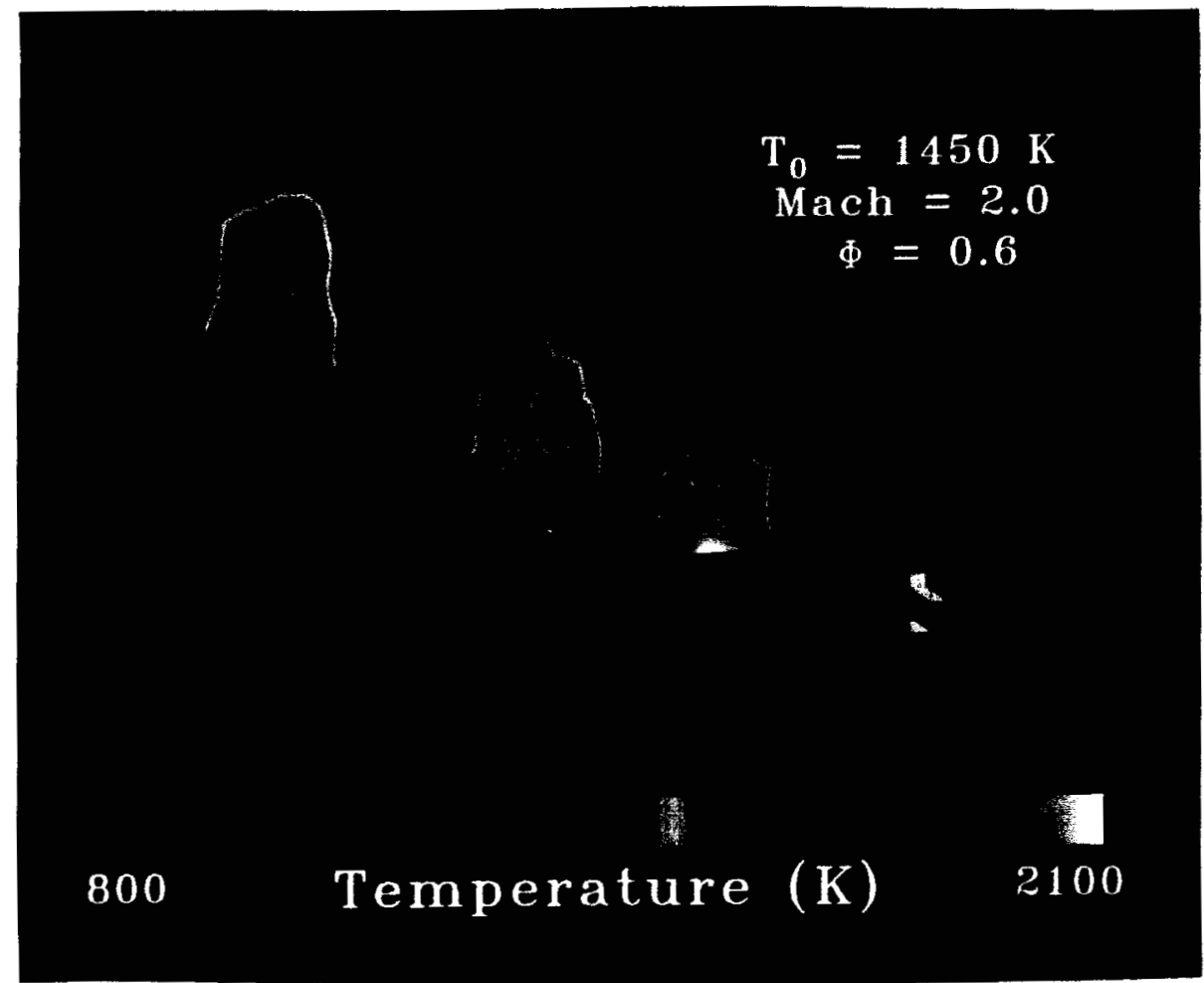

Figure 4 Summary of mean temperature data, cross sctions at three downstream positions.
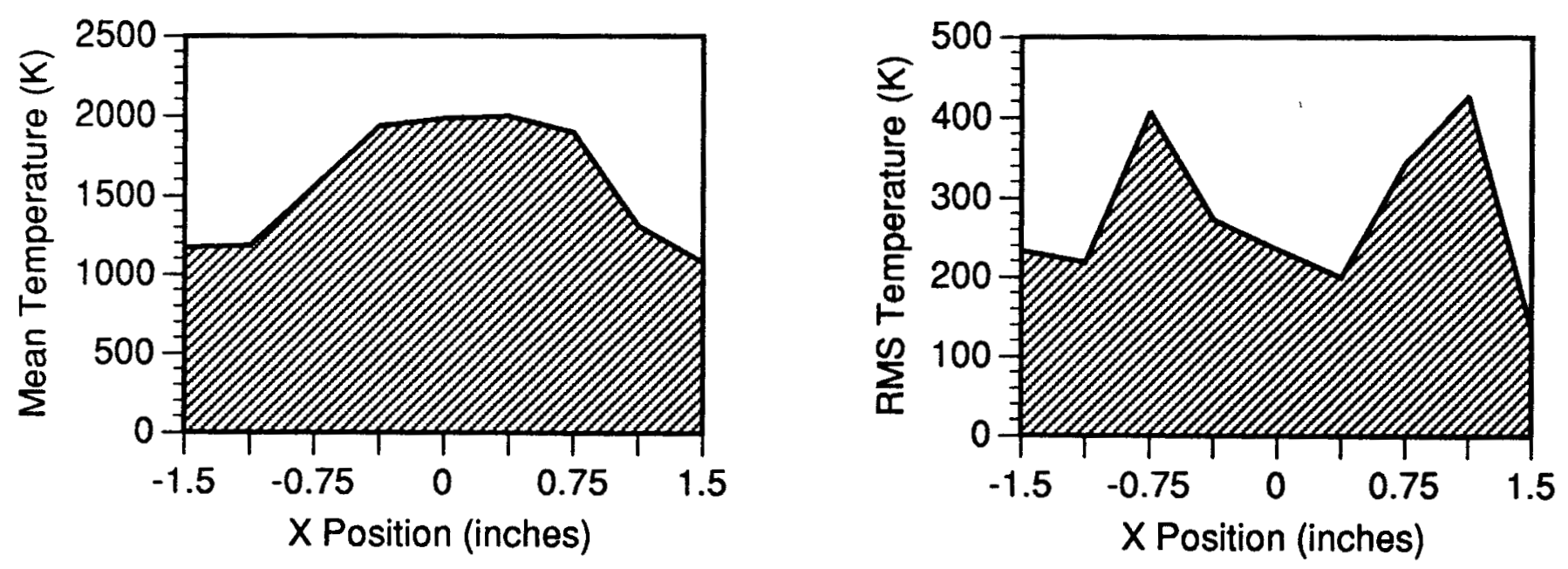

Figures $5 a, b$ Mean and RMS temperature profiles at $y=0.56$ in station 1 . 


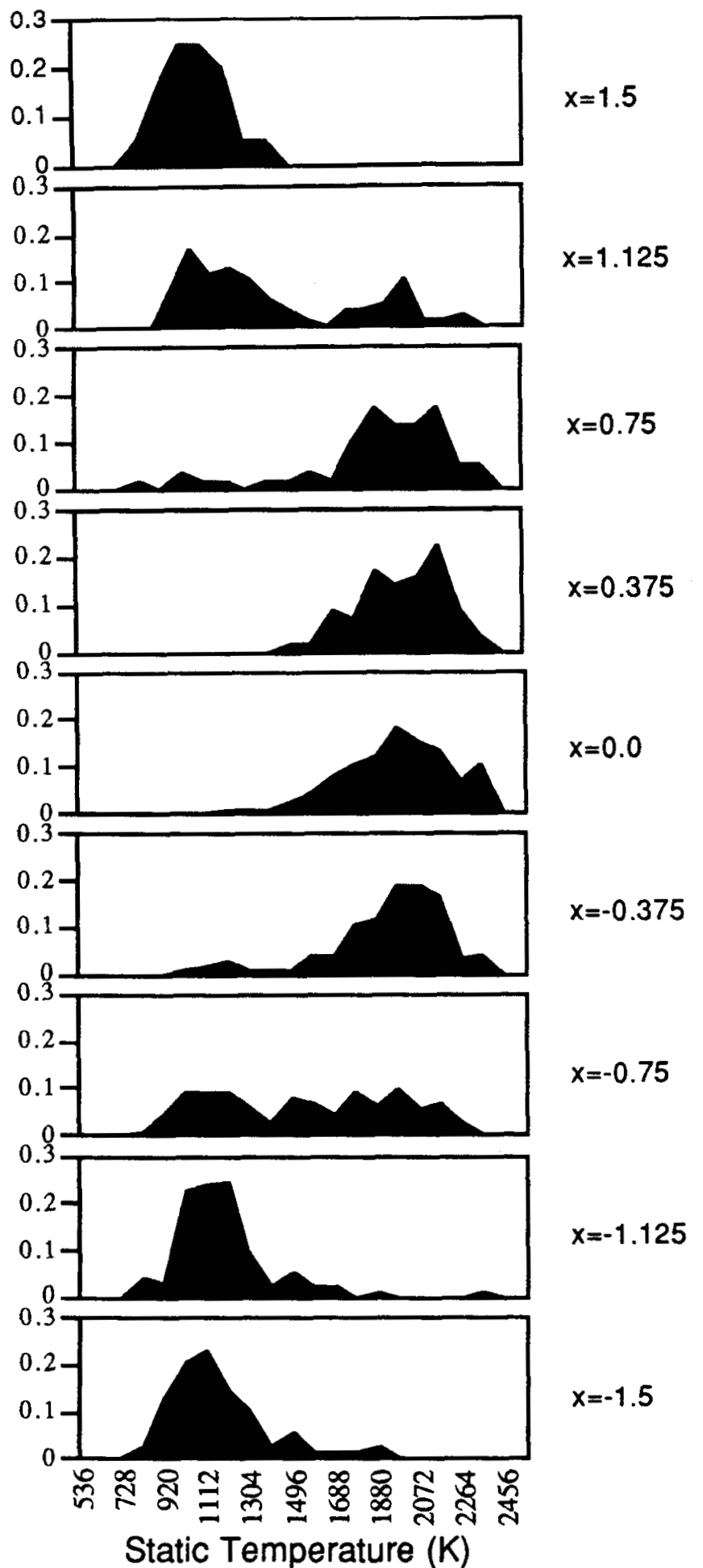

Figure 6. Probability distribution functions of temperature along the $y=0.56$ profile of station 1, with hydrogen injection.

a profile of the data at one particular vertical location $\left[y=0.56^{\prime \prime}\right]$ and station. This appears as a smooth transition from cooler gas to hot combustion gas and back down again. Looking at the RMS of the temperature measurements [Figure 5b] we find large peaks of fluctuation in the transition regions. The reason for these large peaks is seen in Figure 6 which shows prabability distribution functions along this profile.. The large RMS values are seen to stem from somewhat bimodal PDF distributions in the transition regions. Such bimodal temparature distributions at the edge of the jet suggest that it's border is instantaneously quite ragged and sharp. In the mean the edge appears "smooth", however, this temperature is the result of alternately sampling hot and cold pockets of fluid. It is conjectured that the hot pockets are part of the fuel jet and the cold pockets are part of the freestream.

\section{Conclusions}

A CARS system has been hardened for application to hypersonic facilities. Temperature measurements have been made in supersonic combustion. These measurements have provided insight into the turbulence properties of a ducted supersonic reacting flow..

Future refinements of the CARS system will include the ability to obtain density measurements, temperature stabilization of the optics "box", remote positioning in the flow direction and an extension to higher repitition rates.

\section{Acknowledgements}

The authors wish to thank the following individuals for their contribution to the successful completion of this project: Diego Capriotti, Barry Lawhorne, Clint Reese, Dennis Williams and Willis Simmons.

\section{References}

1 A.C. Eckbreth, G.M. Dobbs, J.H. Stufflebeam, and P.A. Tellex, "CARS temperature and species measurements in augmented jet engine exhausts," Applied Optics, Vol. 23 (9), p 1328, (1984).

2 G.L. Switzer, L.P. Goss, D.D. Trump, C.M. Reeves, J.S. Stutrud, R.P. Bradley and W.M. Roquemore, "CARS Measurements in the Near-Wake Region of an Axisymmetric Bluff-Body Combustor," AIAA-85-1106, presented at the AIAA/ SAE/ ASME/ ASEE 21st Joint Propulsion Conference, July 8-10, Monteray, CA, (1985). 
3 R.P. Lucht, R.E. Teets, R.M. Green, R.E. Palmer and $C R$. Ferguson, "Unburned Gas Temperatures in an Internal Combustion Engine. I: CARS Temperature Measurements," Combustion Science and Technology, Vol 55, p 41, (1987).

4 R.R. Antcliff and $O$. Jarrett, Jr., "Multispecies coherent anti-Stokes Raman scattering instrument for turbulent combustion," Review of Scientific Instrumentation, Vol 58(11), $p$ 2075, (1987).

5 S. Fujii, M. Gomi and Y. Jin, "Instantaneous CARS Thermometry in Turbulent Flames," Combustion and Flame Vol 48, p.232, (1982).

6 R.R. Antcliff, M.E. Hillard and O. Jarrett, Jr., "Intensified Silicon Photodiode Array Linearity: Application to Coherent antiStokes Spectroscopy," Applied Optics, Vol 23 (14), p 2369, (1984).

7 A. Cutler, "Fiber-Optic Coupler and Dynamic-Range Enhancer for CARS," NASA Tech Brief, November, (1990).

8 A.C. Eckbreth, "Optical Splitter for Dynamic Range Enhancement of Optical Multichannel Detectors," Applied Optics, Vol 22(14),p 2118, (1983).

9 M. Smith, R. Antcliff, A. Cutler, O. Jarrett, G. Northam and D. Taylor, "CARS Temperature Mcasurements in a Hydrogen-Fueled Supersonic Combustor," AIAA-90-5260, presented at the AIAA 2nd International Aerospace Planes Conference, 29-31 October, Orlando, FL, (1990). 